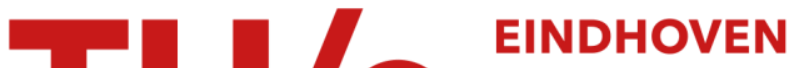 UNIVERSITY OF TECHNOLOGY
}

\section{An energy-efficient and reconfigurable sensor IC for bio- impedance spectroscopy and ECG recording}

Citation for published version (APA):

Xu, J., Harpe, P., \& Van Hoof, C. (2018). An energy-efficient and reconfigurable sensor IC for bio-impedance spectroscopy and ECG recording. IEEE Journal on Emerging and Selected Topics in Circuits and Systems, 8(3), 616-626. [8355772]. https://doi.org/10.1109/JETCAS.2018.2834140

DOI:

10.1109/JETCAS.2018.2834140

Document status and date:

Published: 01/09/2018

\section{Document Version:}

Accepted manuscript including changes made at the peer-review stage

\section{Please check the document version of this publication:}

- A submitted manuscript is the version of the article upon submission and before peer-review. There can be important differences between the submitted version and the official published version of record. People interested in the research are advised to contact the author for the final version of the publication, or visit the $\mathrm{DOI}$ to the publisher's website.

- The final author version and the galley proof are versions of the publication after peer review.

- The final published version features the final layout of the paper including the volume, issue and page numbers.

Link to publication

\section{General rights}

Copyright and moral rights for the publications made accessible in the public portal are retained by the authors and/or other copyright owners and it is a condition of accessing publications that users recognise and abide by the legal requirements associated with these rights.

- Users may download and print one copy of any publication from the public portal for the purpose of private study or research.

- You may not further distribute the material or use it for any profit-making activity or commercial gain

- You may freely distribute the URL identifying the publication in the public portal.

If the publication is distributed under the terms of Article 25fa of the Dutch Copyright Act, indicated by the "Taverne" license above, please follow below link for the End User Agreement:

www.tue.nl/taverne

Take down policy

If you believe that this document breaches copyright please contact us at:

openaccess@tue.nl

providing details and we will investigate your claim. 


\title{
An Energy-Efficient and Reconfigurable Sensor IC for Bio-Impedance Spectroscopy and ECG Recording
}

\author{
Jiawei Xu, Pieter Harpe, Senior Member, IEEE, and Chris Van Hoof
}

\begin{abstract}
This paper presents a low power reconfigurable IC for wearable health devices that perform bio-impedance (BioZ) spectroscopy, respiration and ECG signals measurement. The IC consists of a broadband excitation current source (I-DAC) and a power efficient readout circuit (RO). Both are highly scalable to mitigate the tradeoff among noise, dynamic range, speed, power and safe current limits. On circuit level, the I-DAC supports two broadband excitation modes based on maximum length sequence (MLS), a flexible selection of frequency points, bandwidth and current magnitude. The RO employs a low noise instrumentation amplifier (IA) and a reconfigurable 8-to-12 bit ADC for flexible sensitivity, dynamic range and speed with an automatic scaling of the power consumption. On system level, calibration of the entire circuit chain, oversampling and MLS averaging further improve the bandwidth, accuracy and sensitivity of BioZ spectroscopy beyond the intrinsic circuit performance. As a result, the BioZ sensor IC achieves $2 \mathrm{~m} \Omega$ sensitivity within $3.3 \mathrm{~m} \Omega-100 \Omega$ range and $0.6 \Omega$ sensitivity within $3.3 \Omega-100 \mathrm{k} \Omega$ range. The $B i o Z$ spectroscopy spans up to $125 \mathrm{kHz}$ while consuming $155 \mu \mathrm{W}$. Furthermore, this IC can measure respiration and ECG simultaneously at a lower sampling rate of $20 \mathrm{kS} / \mathrm{s}$ while consuming $31 \mu \mathrm{W}$. Compared to prior art, to the authors' knowledge, this IC is the only work that can measure BioZ and ECG simultaneously with a single readout channel while consuming the lowest power and offering the highest flexibility in performance, application range, and power consumption.
\end{abstract}

Index Terms - bio-impedance, spectroscopy, maximum length sequence, calibration, ECG.

\section{INTRODUCTION}

$\mathrm{T}$ he development of miniaturized wearable medical sensors has been accelerated by ever-increasing chronic diseases, such as emphysema, diabetes, sleep apnea and congestive heart failure. Long-term and continuous monitoring of patients helps to achieve quality and cost-effective healthcare. Thanks to the advances in sensor technology, system integration and signal processing, ultra-low power and miniaturized wearable medical devices enable point-of-care monitoring during patients' daily routine, while still providing medical grade signal quality.

Bio-impedance (BioZ) spectroscopy has been widely used to evaluate biological conditions of tissues, such as fluid overload, respiration, skin hydration, and body composition. The primary use case of BioZ spectroscopy is early detection of congestive heart failure, a chronic but fatal heart disease characterized by fluid overload [1]. Continuous examination of fluid status via wearable BioZ sensors enables self-management and the early detection of heart failure [2]. Furthermore, ECG and respiration patterns are also key indicators of deteriorated heart condition. Sensors combing both the ECG and BioZ functionalities would significantly improve diagnosis quality [3].

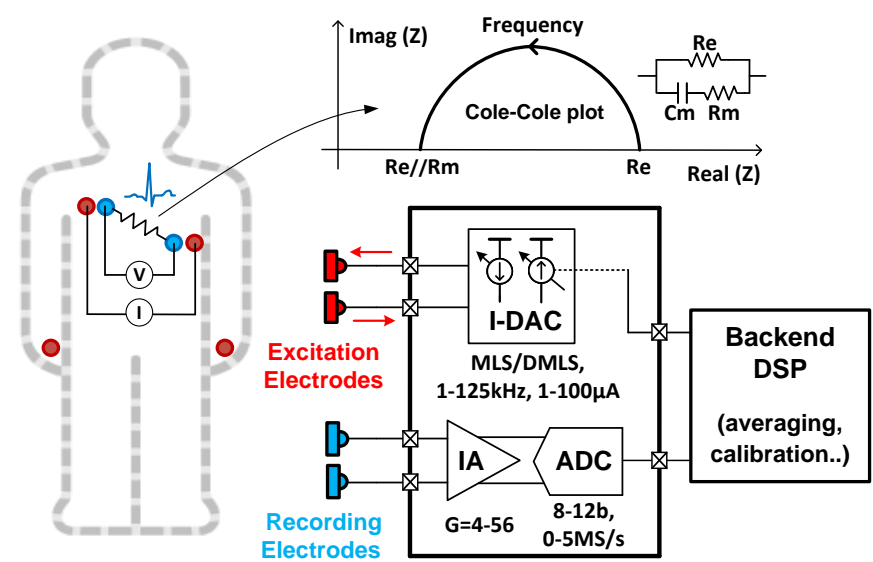

Fig. 1. A reconfigurable sensor IC for BioZ spectroscopy and ECG

State-of-the-art low power ECG [4][5] and BioZ acquisition ICs [6]-[8] have exhibited promising performance. However, combining both the modalities in an ultra-low-power and areaefficient manner remains challenging [9]. Furthermore, prior BioZ spectroscopy ICs [6]-[9] measure the frequency response of BioZ by frequency sweep, resulting in a long measurement time. Conversely, broadband stimulation and direct collection of the BioZ response [10] shortens the measuring time at the cost of more power. In addition, broadband BioZ spectroscopy may exhibit a low precision at low frequencies due to the safe current limits for electromedical apparatus, i.e. maximum $1 \mu \mathrm{A}$ excitation current at and below $100 \mathrm{~Hz}$ [11]. In case of equally distributed excitation current over frequency, the current above $100 \mathrm{~Hz}$ would be limited to $1 \mu \mathrm{A}$ too, resulting in an unnecessary limited signal-to-noise ratio (SNR) from $100 \mathrm{~Hz}$ onwards.

This paper, as an extension of [12], presents a low-power and highly reconfigurable BioZ spectroscopy IC (Fig. 1) based on broadband current excitation, and with simultaneous ECG and respiration recording capabilities. The reconfigurability allows to dynamically scale power with performance (e.g. sensitivity, bandwidth, and dynamic range) and with operating mode (e.g. broadband BioZ spectroscopy, ECG and respiration recording), while reusing the same readout. The primary tradeoff between energy and signal quality is scalable by multiple techniques: a differentiated maximum length sequence (DMLS) for better compliance to the safe current regulations; calibration for BioZ accuracy improvement and bandwidth extension; oversampling and averaging of MLS for improved sensitivity. On IC level, a reconfigurable excitation current source (I-DAC), a low-noise instrumentation amplifier (IA) and an 8-to-12 bit ADC provide scaling flexibility for noise, dynamic range, bandwidth, power consumption and safe current compliance. The IC can measure resistors from $3.3 \mathrm{~m} \Omega$ up to $100 \Omega$ with a $2 \mathrm{~m} \Omega$ sensitivity, or 
resistors from $3.3 \Omega$ up to $100 \mathrm{k} \Omega$ with a $0.6 \Omega$ sensitivity, while the measurement bandwidth is maximum $125 \mathrm{kHz}$. In case of simultaneous measurement of respiratory impedance and ECG, the IC consumes $31 \mu \mathrm{W}$ when sampling at $20 \mathrm{kS} / \mathrm{s}$.

\section{SYSTEM ARCHITECTURE}

\section{A. System Specifications}

The IC (Fig. 2) contains an (D)MLS-based I-DAC, a low noise IA, and an 8-to-12 bit SAR ADC. The I-DAC applies a $\mu \mathrm{A}-$ level AC current to body, and an AC voltage proportional to BioZ is amplified by the readout circuitry [13]. On system level, a HPF placed at the I-DAC output blocks any DC current flowing to the subject for patient safety. Another HPF rejects a large electrode offset to the IA and provides its DC biasing at $\mathrm{V}_{\mathrm{dd}} / 2$. This improves the dynamic range and prevents saturation of the IA especially when both large BioZ signals and electrode offset appear at the input. Post-processing of digital signals is done off chip in software.

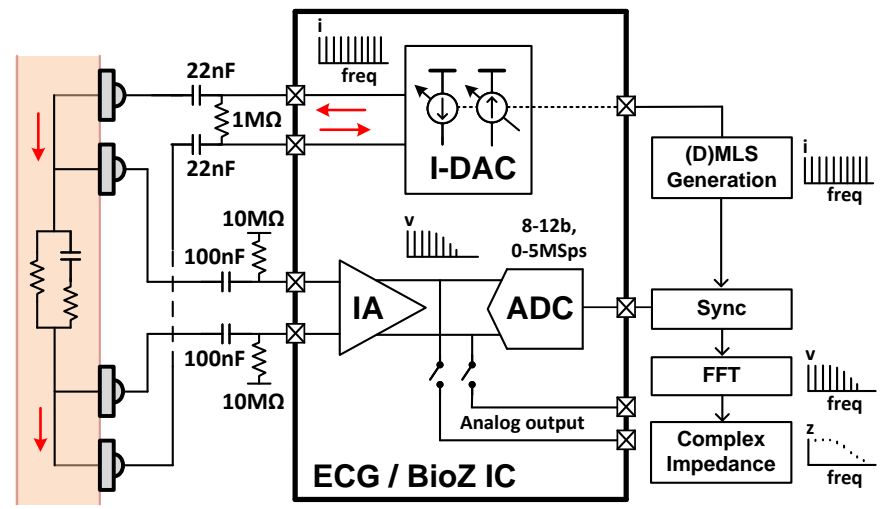

Fig. 2. System diagram of the ECG/BioZ sensor IC

To reduce system power and chip area, the IC measures BioZ and ECG simultaneously by making use of their difference in frequency bands (Fig. 3). The BioZ can be measured between $1 \mathrm{kHz}$ to $1 \mathrm{MHz}$, while the ECG bandwidth is less than $150 \mathrm{~Hz}$. Thus, the excitation current for the BioZ is designed to contain energy only above $200 \mathrm{~Hz}$. In this way, both ECG and BioZ can be measured by the same IA and ADC, allowing for separation by digital filters. The respiration rate can be derived from the time-variant BioZ at a single frequency (e.g. $1 \mathrm{k}-10 \mathrm{kHz})$.

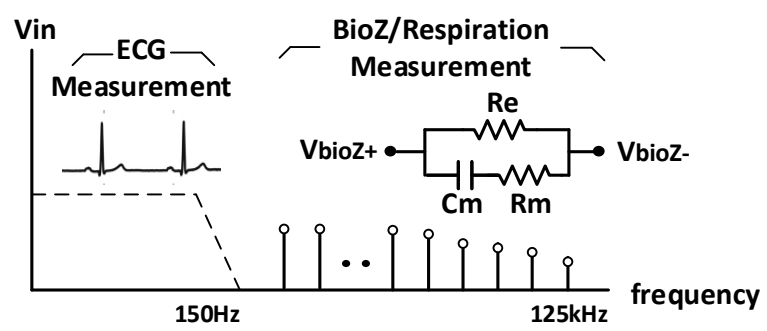

Fig. 3. Principle of simultaneous ECG/BioZ/respiration measurement

BioZ can be modeled as a static impedance $(1 \Omega-1 \mathrm{k} \Omega)$ and a series connected dynamic impedance $(10 \mathrm{~m} \Omega-1 \Omega)$. To detect small BioZ changes like fluid volume, the readout should attain high sensitivity $(<10 \mathrm{~m} \Omega)$ while being able to cope with a large static impedance without saturating the amplifier. This means a very large dynamic range $(>100 \mathrm{~dB})$ is needed for measuring
BioZ. In addition, BioZ spectroscopy requires a bandwidth of at least $100 \mathrm{kHz}$ to measure the entire impedance transfer function. Lastly, throughout the entire bandwidth, the peak magnitude of the I-DAC must be compliant to safe current limits [11][14].

Ambulatory ECG specifications are often determined by the IEC standards [15][16], which defines necessary input referred noise $\left(<50 \mu \mathrm{V}_{\mathrm{pp}}\right)$, input impedance $(>10 \mathrm{M} \Omega)$, CMRR $(>60 \mathrm{~dB})$ and DC electrode offset tolerance $( \pm 300 \mathrm{mV})$. A dynamic range of $60 \mathrm{~dB}$ or more is beneficial when considering motion artifacts superimposed on the ECG.

\section{B. Broadband Current Excitation}

Broadband excitation can be realized in different ways (Fig. 4). A single-frequency (SF) excitation has a high SNR, because the excitation power is concentrated at one frequency (Fig. 4a). State-of-the-art BioZ readouts employ synchronous modulation [8][9][17][18], where the upmodulated BioZ input signal is first demodulated to baseband before entering the IA. This reduces the required IA bandwidth and associated power. However, a broadband BioZ spectroscopy then needs to sweep multiple frequencies sequentially. This results in a long acquisition time, because the settling time for each frequency is accumulated.

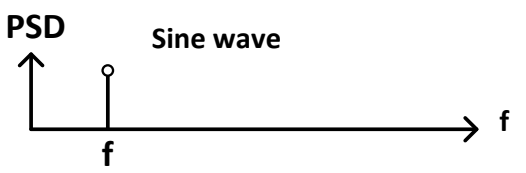

a)

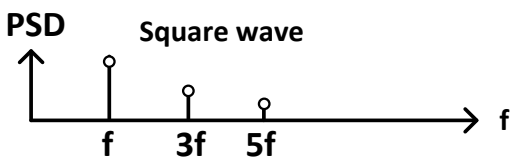

b)

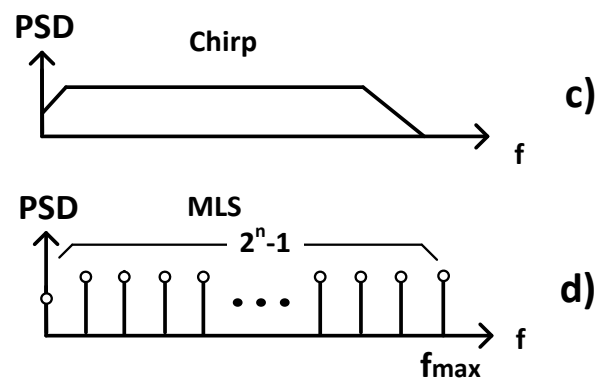

Fig. 4. Spectrum illustration of: a) sine, b) square, c) chirp and d) MLS

Broadband BioZ spectroscopy reduces its measurement time by applying multi-frequency tones at once [19]. In [10], it takes only $1 \mathrm{~ms}$ to measure 512 frequency components between $1 \mathrm{kHz}$ to $500 \mathrm{kHz}$. Typical broadband excitation patterns include chirp, square wave, or pseudo-random sequence. A chirp is not easy to generate and often suffers from a low SNR, because the power is spread over the entire bandwidth (Fig. 4c). A square wave is easy to generate, but it also has a rapidly declining SNR at harmonic frequencies (Fig. 4b). A pseudo-random sequence combines the benefits of a chirp and a square wave, i.e. reconfigurable, easy to generate, and retains an equal SNR at each frequency bin. This work utilizes the maximum length sequence (MLS) [20], i.e., a pseudo random pulse train with an almost evenly distributed multi-tone spectrum (Fig. 4d).

The IC supports two MLS modes (Fig. 5): a standard MLS 
and a differentiated MLS, namely DMLS, which is basically a high-passed MLS. In standard MLS mode, the I-DAC outputs 1-bit current pulses with a peak magnitude of $\pm I_{\text {ref. }}$ In the DMLS mode, a filter function is realized by applying a digital differentiator with a transfer function of $\left(1-Z^{-1}\right) / 2$ to an MLS. This filter, applied to a 1-bit MLS, results in a 1.5-bit DMLS sequence. Therefore, the I-DAC now outputs a 1.5-bit current pulse sequence with levels of $-\mathrm{I}_{\text {ref, }}, 0$, and $+\mathrm{I}_{\text {ref }}$ (Fig. 5). Both MLS and DMLS have $2^{n}-1$ frequency components, uniformly distributed at:

$$
f(k)=\frac{k f_{s}}{2^{n}-1}
$$

where $f_{s}$ is the (D)MLS sampling frequency, $n$ is the (D)MLS order $\left(0 \leq k \leq 2^{n}-1\right) \cdot f_{s}$ and $n$ define the bandwidth and the number of frequency points of the BioZ spectroscopy (Fig. 4d) and they can be controlled digitally.

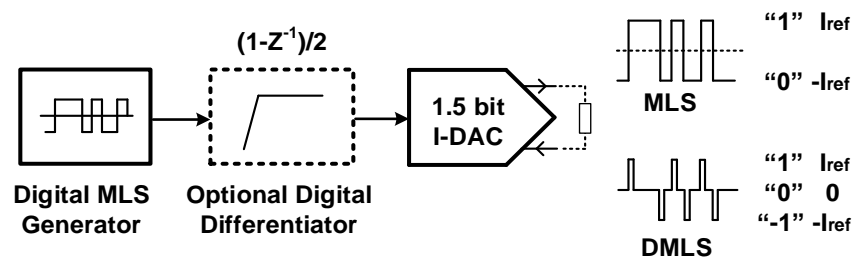

Fig. 5. Generation of broadband stimulation signals: MLS and DMLS

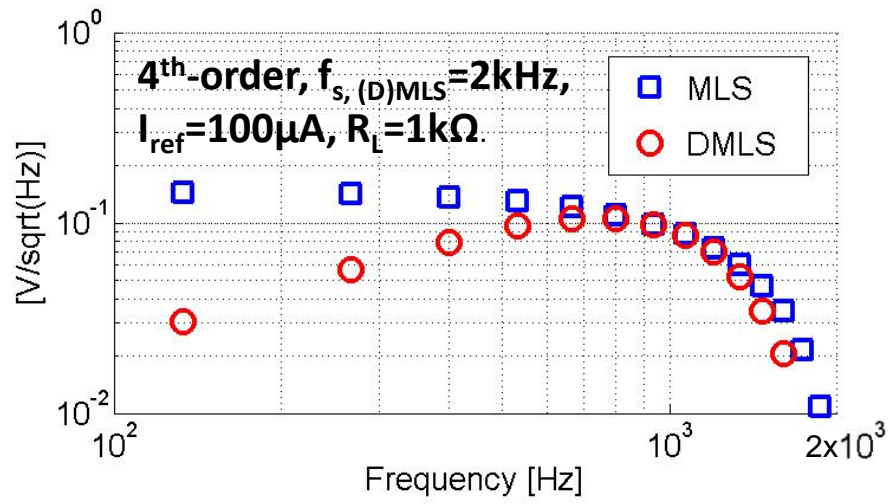

Fig. 6. Simulated input (D)MLS signal at the input of the IA

Fig. 6 shows the simulated voltage spectrum attributed to a (D)MLS excitation current flowing through a test resistor. The DMLS curve exhibits a high-pass characteristic indicating less excitation current below $600 \mathrm{~Hz}$. The rolling off above $1 \mathrm{kHz}$ is due to the I-DAC's sinc function.

The high-pass feature of DMLS makes it a better option than MLS for BioZ spectroscopy. Firstly, DMLS suits better to the safe current limits (Fig. 7a) [11] and enables a better SNR at higher frequencies by injecting more current where possible. Secondly, the "high-pass" DMLS current is complementary to the "low-pass" BioZ in frequency band (Fig. 7b). This partially compensates the frequency dependence of the BioZ and thus relaxes the dynamic range and the SNR requirements for the IA. Thirdly, the DMLS also counteracts the roll-off due to the IA's finite bandwidth (Fig. 7c). This can be considered as bandwidth extension of the system transfer function (Fig. 7d) even though the SNR beyond the IA's -3dB bandwidth will eventually drop.
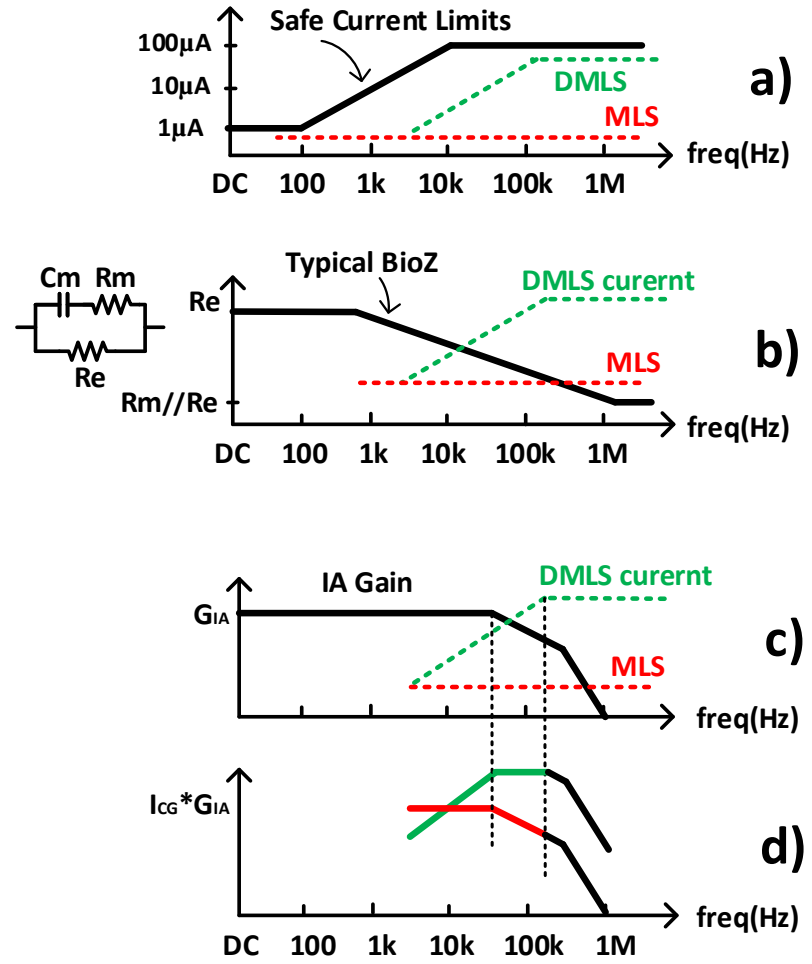

Fig. 7. The frequency characteristics of a) safe current limits [11], b) typical BioZ model, c) typical IA's transfer function, and d) overall system transfer function

\section{Digital Signal Post-Processing}

It is possible to improve the accuracy and sensitivity of BioZ spectroscopy on system level (Fig. 8). Since the (D)MLS has a repetitive pattern, averaging multiple responses to a (D)MLS excitation in the digital backend can reduce uncorrelated noise. In addition, the ADC can be oversampled (up to $5 \mathrm{MS} / \mathrm{s}$ in this work) to reduce its noise contribution.

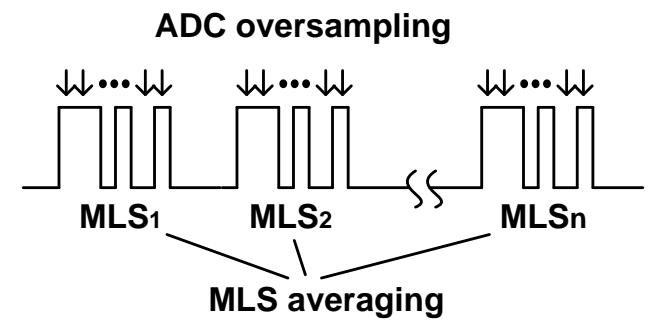

Fig. 8. ADC oversampling and (D)MLS averaging for noise reduction

Apart from averaging and oversampling, calibration with a reference resistor (Fig. 9) can improve the BioZ measurement accuracy too. This is realized by normalizing the BioZ output $V_{2}(f)$ to the reference measurement $V_{1}(f)$. Static system errors, such as the non-ideal frequency-dependent transfer functions of I-DAC, IA, and ADC, are compensated in the first order.

The data processing flow for simultaneous recording of ECG, BioZ and respiration is illustrated in Fig. 10, where the system utilizes a $20 \mathrm{kS} / \mathrm{s}, 6^{\text {th }}$-order $10 \mu \mathrm{A}$ (D)MLS current as example. The lowest frequency component of the (D)MLS is at $317 \mathrm{~Hz}$ to avoid overlap with the ECG. The ECG is obtained by streaming 
out the ADC's outputs and filtering by a $100 \mathrm{~Hz}$ LPF. The BioZ is obtained by synchronizing the ADC output with the (D)MLS reference, then performing FFT and finally dividing the result with the calibration measurement to get the complex BioZ at all frequency points. Respiratory impedance is derived from the BioZ spectroscopy over a selected frequency interval between $7 \mathrm{kHz}$ and $10 \mathrm{kHz}$.
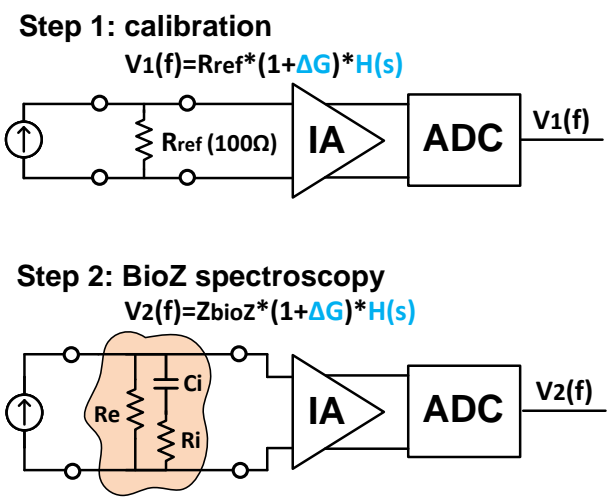

Fig. 9. Calibration to reduce the static errors in I-DAC, IA and ADC

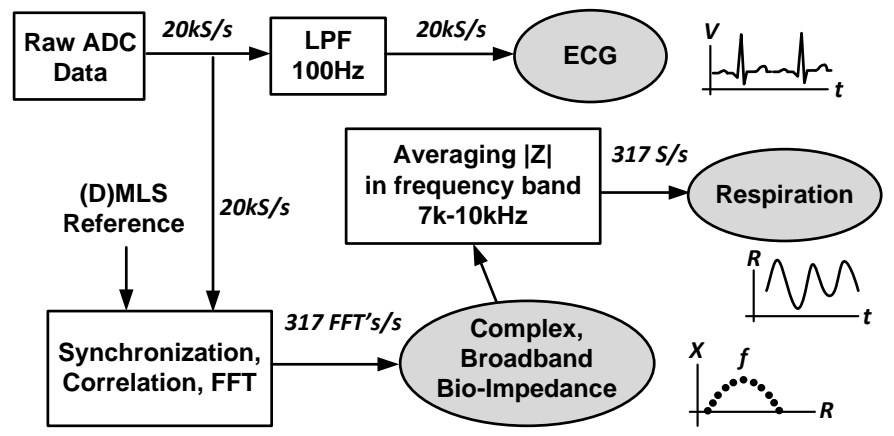

Fig. 10. Data processing flow of ECG, BioZ and respiration

\section{IC BUILDING BLOCKS}

\section{A. Current-Steering DAC (I-DAC)}

The I-DAC (Fig. 11) is implemented in a bipolar mode, in which the differential outputs are driven at an opposite polarity [21]. A cascode NMOS current source is used to increase the output impedance. Three control signals (DP, DN, and DZ) configure the I-DAC either to a 1-bit MLS mode, or to a 1.5-bit DMLS mode. The output current is reconfigurable from $1 \mu \mathrm{A}$ to $100 \mu \mathrm{A}$ and supports clock rate up to $1 \mathrm{MHz}$.

Compared with a monopolar mode I-DAC with both sinking and sourcing currents [6]-[9], the bipolar I-DAC offers a higher output dynamic range. Secondly, the mismatch between $\pm \mathrm{I}_{\mathrm{ref}}$ is minimized because they share the same tail current. When both currents are switched off, the third branch $(\mathrm{DZ}=1)$ maintains the DC bias of the tail current source for dynamic linearity.

In terms of flexibility, the clock rate of the I-DAC sets the overall excitation bandwidth and the tail current determines the excitation amplitude.

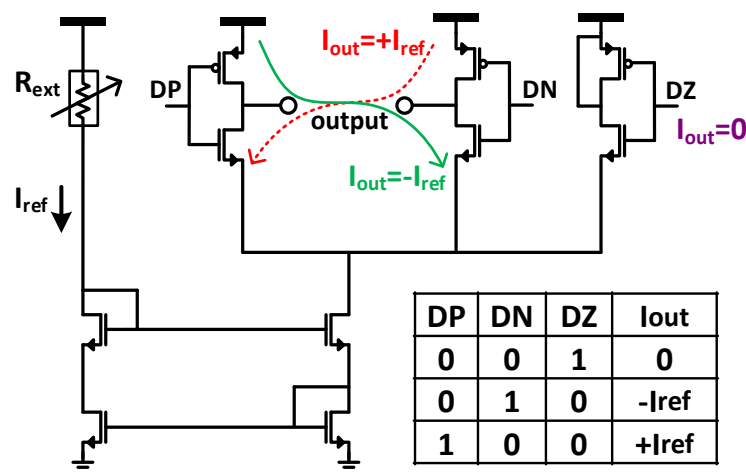

Fig. 11. 1b/1.5b current DAC (I-DAC)

\section{B. Instrumentation Amplifier (IA)}

The IA utilizes a current balancing architecture (Fig. 12) [22] for a high input impedance and a reconfigurable voltage gain. The input resistor $\mathrm{R}_{\mathrm{i}}$ converts the differential input voltage into current through PMOS current mirrors, and then the differential output voltage is obtained via output resistor $R_{0}$. Thus, the IA gain is defined by $R_{0} / R_{i}$, where $R_{i}$ is reconfigurable from $10 \mathrm{k} \Omega$, $41 \mathrm{k} \Omega$ and $175 \mathrm{k} \Omega$. This sets multiple gain settings of 4,17 and $70 \mathrm{~V} / \mathrm{V}$ to measure the ECG and BioZ simultaneously. An input dynamic range of more than $15 \mathrm{mV}_{\mathrm{pp}}$ is sufficient to tolerate motion artifacts and mains interferences. The actual measured IA gain is reduced to 4,15 and $56 \mathrm{~V} / \mathrm{V}$ due to the on-resistance of switches connected to $R_{i}$ in series. The IA has a bandwidth of $35 \mathrm{kHz}$ while consuming $7.4 \mu \mathrm{A}$. For power reduction purpose, the bandwidth is chosen around the typical BioZ measurement frequency of $50 \mathrm{kHz}$, but high-frequency BioZ measurements up to $125 \mathrm{kHz}$ are still possible by means of calibration and the DMLS excitation mode.

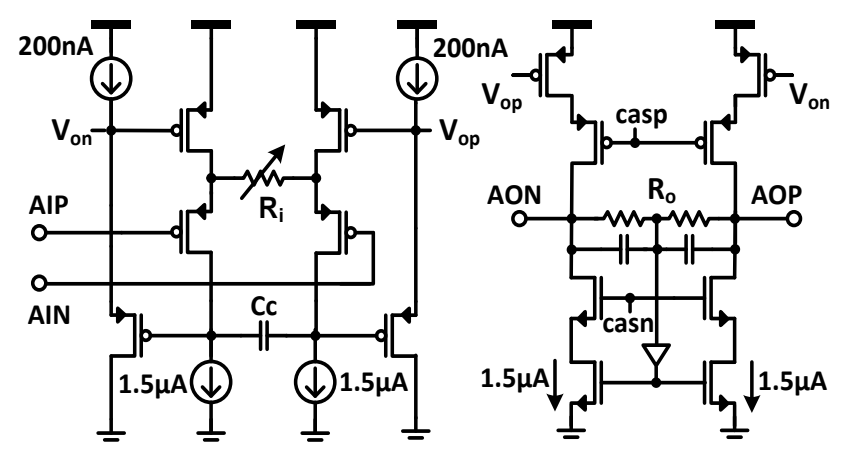

Fig. 12. Schematic of the current balancing IA.

C. 8-to-12 bit SAR ADC
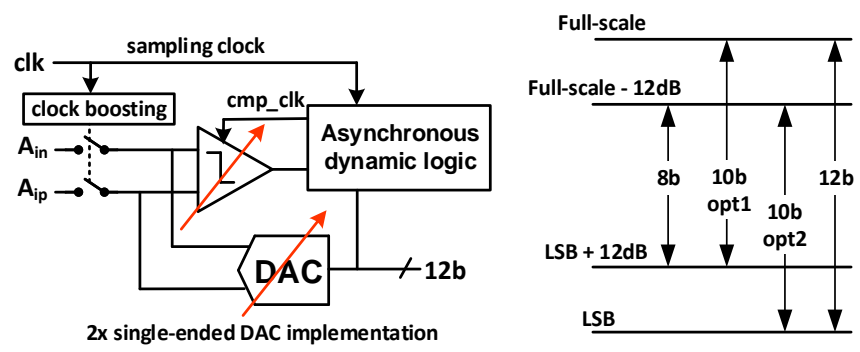

Fig. 13. 8-to-12 bit asynchronous SAR ADC 

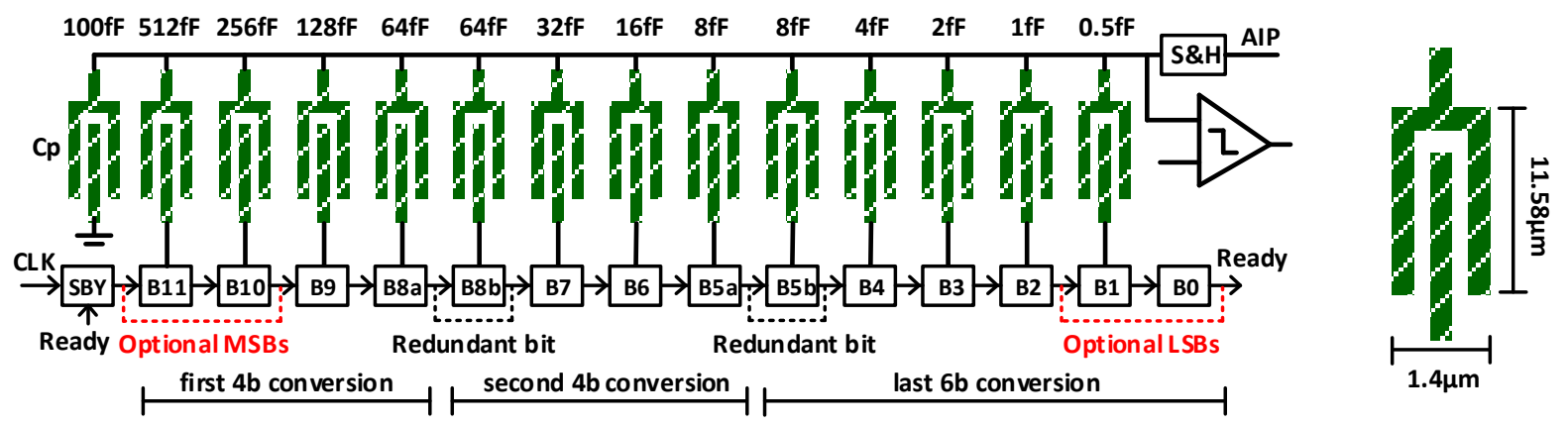

Fig. 14. Half DAC with optional MSBs/LSBs, monotonic switching, metal finger capacitors, and redundant bits

A reconfigurable $\mathrm{ADC}$ offers improved flexibility of resolution, speed, power and chip area [23]. The asynchronous 8-to-12 bit ADC (Fig. 13) is an extension of a previous 7-to-10 bit ADC [24], but with a higher ENOB and a maximum sampling rate of up to $5 \mathrm{MS} / \mathrm{s}$ for broadband BioZ spectroscopy. 8-to-10 bit resolution modes reduce the ADC and DSP power when the requirement on sensitivity or dynamic range is relaxed (e.g. respiration rate detection or ECG-only measurement). Thanks to the dynamic circuitry, the ADC power scales inherently with the actual sample rate. Moreover, the comparator and DAC are reconfigurable to adjust the dynamic range and resolution. Four resolution modes are illustrated in Fig. 13. In 12-bit mode, the maximum dynamic range and best sensitivity are achieved by enabling all bits of the DAC and using the comparator in a setting with lowest noise. Two 10-bit modes are supported by either disabling the 2 MSBs or the 2 LSBs of the DAC (Fig. 14), thus either reducing the full-scale or reducing the sensitivity by 2 bits. Lastly, 8-bit operation can be achieved by omitting both the MSBs and LSBs. Dependent on the selected mode, power can be saved in the DAC by disabling some of the switched capacitors or in the comparator (Fig. 15) by relaxing the noise performance. A two-stage dynamic comparator (Fig. 15) [25] consists of a reconfigurable preamplifier and a latch with rail-to-rail output. The load capacitor of the preamplifier poses a tradeoff between power and noise [26], which are optimized by configuring this capacitor between $0-70 \mathrm{fF}$. The tail current can be increased to compensate speed reduction due to a large load capacitance.

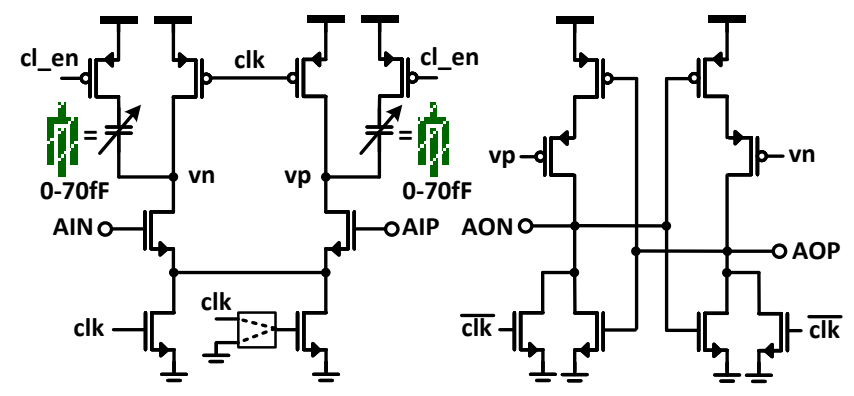

Fig. 15. Comparator with reconfigurable capacitance and tail current

The switching power of the DAC may constitute a significant portion of the ADC's total power dissipation. Key approaches to reduce the switching power are to use an energy-efficient switching scheme [27] and to reduce overall DAC capacitance. This ADC utilizes a charge-redistribution DAC with monotonic switching [26] and custom designed metal finger capacitors [24] of $0.5 \mathrm{fF}$ to save power and chip area. These metal finger capacitors (Fig. 14), implemented on both metal layers 4 and 5, achieve a unit-element capacitor of $0.5 \mathrm{fF}$. This value is achieved by sizing the dimensions of the metal structure manually, and using regular RC-extraction tools to estimate the nominal capacitor value. A shielding plate on metal layer 1, placed underneath the capacitor array, minimizes noise coupling to the substrate. To further reduce the power, the DAC utilizes a 3-step conversion [28], in which two redundant bits (B8a, B8b and B5a, B5b) are used (Fig. 14), enabling to save comparator power in the first 2 steps of the conversion, similar to [24]. Note that the DAC topology is parasitic insensitive: parasitics at the output node $\left(\mathrm{C}_{\mathrm{p}} \approx 100 \mathrm{fF}\right)$ only cause a gain factor, while parasitics at the logic side of the capacitors only cause increased power consumption, without changing the DAC transfer function.

On system level, the ADC's low input capacitance of $1.2 \mathrm{pF}$ (per side) eliminates the need of a dedicated ADC driver to save power. The ADC's total noise is $0.27 \mathrm{mV}_{\mathrm{rms}}$ and further reduced to $4.82 \mu \mathrm{V}_{\mathrm{rms}}$ when referred to the IA's input $\left(\mathrm{G}_{\mathrm{IA}}=56 \mathrm{~V} / \mathrm{V}\right)$. In addition, oversampling can further average the in-band ADC noise down to a fraction of the above-mentioned numbers. For instance, when the ADC is sampled at $2 \mathrm{MS} / \mathrm{s}$, the noise in a $100 \mathrm{~Hz}$ bandwidth is only $50 \mathrm{nV}_{\text {rms }}$ referred to the IA's input.

In terms of flexibility, the clock rate of the ADC can be used to adjust the MLS bandwidth or to improve the SNR (by means of oversampling), while the resolution is between 8-to-12 bit. In all cases, the power scales automatically according to the active setting.

\section{PARAMETER ANALYSIS}

The tradeoffs of performance matrix and power consumption are summarized and discussed in this section. Key parameters can be improved by the proposed reconfigurations (TABLE I). Among these parameters, frequency points and safe current limits were discussed previously.

\section{A. Bandwidth}

The bandwidth of BioZ spectroscopy is initially limited by the IA's bandwidth of 35kHz. Beyond this frequency, the SNR is reduced. Nevertheless, enabling either the DMLS mode or the calibration can compensate the frequency dependencies of the overall transfer function, improving the SNR beyond $35 \mathrm{kHz}$. In this work, BioZ spectroscopy combining both DMLS and 
calibration, can measure BioZ up to a frequency of $125 \mathrm{kHz}$ (see Section V.D). This is roughly a factor of $3.5 \mathrm{x}$ improvement compared to the IA's initial bandwidth. On the other side, the lowest frequency bin of the BioZ spectroscopy can be reduced towards the ECG bandwidth of $150 \mathrm{~Hz}$ by increasing the MLS order or by reducing the MLS clock rate (see eqn. (1)).

TABLE I: IC RECONFIGURATION FOR PARAMETER ADAPTABILITY

\begin{tabular}{|c|c|c|}
\hline Parameters & Range & Proposed Reconfiguration \\
\hline Bandwidth & $<125 \mathrm{kHz}$ & $\begin{array}{l}\text { Enable DMLS to expand } \\
\text { Enable Calibration to expand } \\
\text { (D)MLS sampling frequency }(\uparrow) \\
\text { ADC sampling frequency }(\uparrow)\end{array}$ \\
\hline Meas. Time & $\sim 1 \mathrm{~ms}$ & $\begin{array}{l}\text { (D)MLS order }(\downarrow) \\
\text { Oversampling and averaging }(\downarrow)\end{array}$ \\
\hline $\begin{array}{l}\text { Frequency } \\
\text { Points }\end{array}$ & $\begin{array}{l}2^{\mathrm{n}}-1 \\
\mathrm{n}: \text { MLS order }\end{array}$ & $\begin{array}{l}\text { (D)MLS order }(\uparrow) \\
\text { ADC sampling frequency }(\uparrow)\end{array}$ \\
\hline $\begin{array}{l}\text { Impedance } \\
\text { Range }\end{array}$ & $\begin{array}{l}3.3 \mathrm{~m}-100 \Omega \\
3.3-100 \mathrm{k} \Omega\end{array}$ & $\begin{array}{l}\text { IA gain }(\downarrow) \\
\text { I-DAC magnitude }(\downarrow) \\
\text { ADC resolution }(\uparrow)\end{array}$ \\
\hline $\begin{array}{l}\text { Impedance } \\
\text { Sensitivity }\end{array}$ & $2 m-0.6 \Omega$ & $\begin{array}{l}\text { Enable MLS mode } \\
\text { I-DAC magnitude }(\uparrow) \\
\text { ADC resolution }(\uparrow) \\
\text { IA gain }(\uparrow) \\
\text { Oversampling and averaging }(\uparrow) \\
\text { Enable Calibration }\end{array}$ \\
\hline $\begin{array}{l}\text { Safe } \\
\text { Current }\end{array}$ & $\begin{array}{l}<100 \mu \mathrm{A} \\
\text { at } 10 \mathrm{kHz}\end{array}$ & $\begin{array}{l}\text { Enable DMLS } \\
\text { I-DAC magnitude }(\downarrow)\end{array}$ \\
\hline $\begin{array}{l}\text { Power } \\
\text { Dissipation }\end{array}$ & $<200 \mu \mathrm{W}$ & $\begin{array}{l}\text { I-DAC magnitude }(\downarrow) \\
\text { Oversampling and averaging }(\downarrow) \\
\text { ADC resolution }(\downarrow) \\
\text { ADC sampling rate }(\downarrow)\end{array}$ \\
\hline
\end{tabular}

\section{B. Measurement Time}

The measurement time of single BioZ spectroscopy with a (D)MLS excitation is determined by its lowest frequency bin. However, the actual measurement time can be $m$ times larger by repeating the sequence $m$ times and averaging the results for a better accuracy. Ideally, the non-correlated measurement errors can be reduced by the square root of $m$.

When implementing broadband BioZ spectroscopy through frequency sweeping rather than (D)MLS, it could contain the same number of frequency points $\left(2^{n}-1\right)$. However, frequency sweeping will take much more time than broadband excitation, as the different frequencies are applied sequentially rather than simultaneously.

\section{Dynamic Range}

The maximum input dynamic range of the BioZ readout is achieved when the IA has the lowest gain of 4 , the ADC is configured to the 12 bit mode and the current excitation is at $1 \mu \mathrm{A}$. Nevertheless, the maximum dynamic range is also limited by the current balancing IA's input stage:

$$
R_{B i o Z, \max }=\frac{R_{i} \cdot I_{b}}{I_{r e f}}
$$

where $R_{i}=175 \mathrm{k} \Omega, I_{b}=1.5 \mu \mathrm{A}$, and $\mathrm{I}_{\mathrm{ref}}=1 \mu \mathrm{A}$ is the minimal output current of the I-DAC. This defines the theoretical maximum BioZ range of $262.5 \mathrm{k} \Omega$. In practice, it is reduced to $100 \mathrm{k} \Omega$ to maintain linearity and proper biasing conditions for the input transistors.

\section{Sensitivity}

The sensitivity of BioZ spectroscopy, based on a single MLS sequence, is determined by the system noise:

$$
\overline{R_{\text {sen }}}=\frac{\sqrt{\left(\overline{I_{\text {outn }, D A C}^{2}} \cdot R_{B i o Z}\right)^{2}+\overline{V_{i n, R O}^{2}}}}{I_{r e f}} \approx \frac{\overline{V_{i n, R O}}}{I_{r e f}}
$$

where $R_{\text {sen }}$ is the BioZ sensitivity, $\mathrm{I}_{\mathrm{ref}}$ is the output current of the I-DAC, $\mathrm{I}_{\text {outn,DAC }}$ is the current noise density of the I-DAC, $\mathrm{R}_{\mathrm{BioZ}}$ is the BioZ resistance, and $V_{i n, R O}$ is the total input referred noise of the readout circuit including the IA and the ADC.

In case $\mathrm{I}_{\mathrm{ref}}=100 \mu \mathrm{A}, \mathrm{G}_{\mathrm{IA}}=56, \mathrm{R}_{\mathrm{BioZ}}=1 \mathrm{k} \Omega, \mathrm{f}_{\mathrm{s}, \mathrm{ADC}}=400 \mathrm{kS} / \mathrm{s}$ and the BioZ spectroscopy has a bandwidth of $25 \mathrm{kHz}$. The input referred noise of the IA and the $A D C$ are $V_{\text {in,IA }}=6.8 \mu V_{\text {rms }}$ and $\mathrm{V}_{\text {in }, A D C}=1.8 \mu \mathrm{V}_{\text {rms }}$ (in $25 \mathrm{kHz} \mathrm{BW}$ ) respectively. This results in a BioZ sensitivity of $70 \mathrm{~m} \Omega_{\mathrm{rms}}$ for a single MLS measurement.

This sensitivity is very close to the actual measured value of $80 \mathrm{~m} \Omega_{\text {rms }}$ with the same system parameters (see Section V.D). In addition, it can be further improved by approximately $(m)^{1 / 2}$ by averaging the (D)MLS sequences $m$ times (see Table II in Section V.D).

\section{E. Power Consumption}

The I-DAC consumes most of the system power. However, reducing I-DAC current is subject to the BioZ sensitivity, the dynamic range of the readout, and the safe current regulation. Power can be saved by reducing the ADC sampling rate and resolution, but this is in conflict to oversampling and averaging of multiple (D)MLS sequences, again reducing the sensitivity. Thanks to the flexibility, the actual settings can be selected for application requirements or the actual use case.

\section{MEASUREMENT RESULTS}

The $2.6 \mathrm{~mm}^{2}$ sensor IC was implemented in a $0.18 \mu \mathrm{m}$ CMOS technology (Fig. 16). The I-DAC, IA and ADC occupy a chip area of $0.02 \mathrm{~mm}^{2}, 0.11 \mathrm{~mm}^{2}$ and $0.15 \mathrm{~mm}^{2}$, respectively.

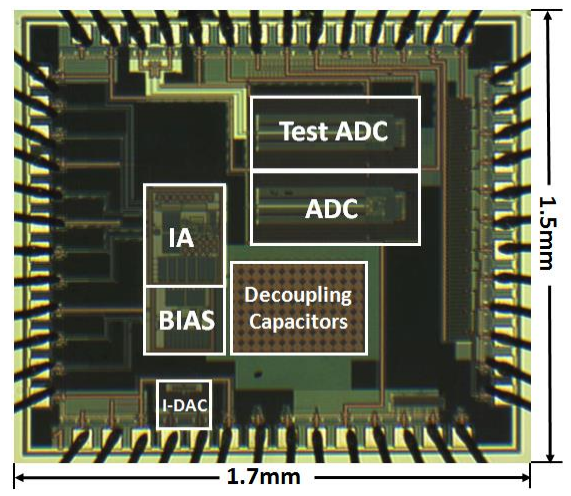

Fig. 16. Chip photograph

\section{A. IA Performance}

Fig. 17 shows the IA gain measured at the analog test output and at the ADC output. The former shows a $3.2 \mathrm{kHz}$ bandwidth limited by external load capacitance at the test output, while an improved bandwidth of $35 \mathrm{kHz}$ is measured at the ADC output. 


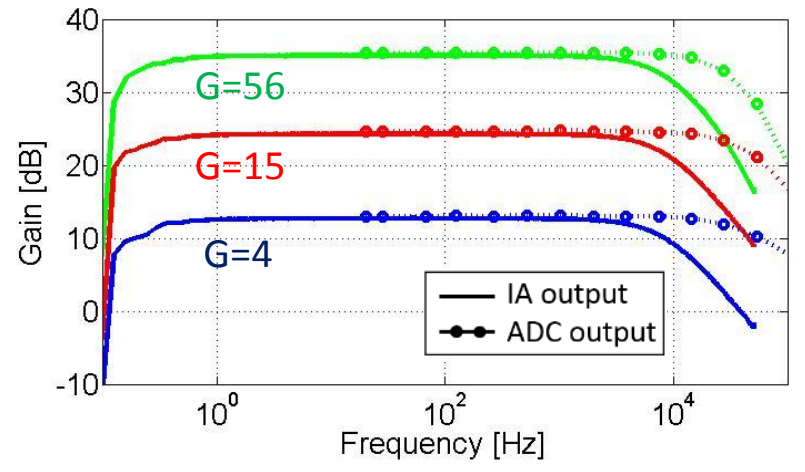

Fig. 17. IA gain measured from analog test output (with external load capacitor) and from ADC output (without external load capacitor)

In Fig. 18, the IA shows $40 \mathrm{nV} / \sqrt{ }(\mathrm{Hz})$ input referred noise at $1 \mathrm{kHz}$ when $\mathrm{G}_{\mathrm{IA}}=56$. The $1 / f$ noise is acceptable because the integrated noise over $150 \mathrm{~Hz}$ bandwidth in all gain settings still meets the IEC noise requirement $\left(<50 \mu \mathrm{V}_{\mathrm{pp}}\right.$, or $\left.\sim 7.5 \mu \mathrm{V}_{\mathrm{rms}}\right)$ [15]. The CMRR and PSRR of the IA (with the external HPF) are 60dB (Fig. 19) and 75dB (Fig. 20), respectively.

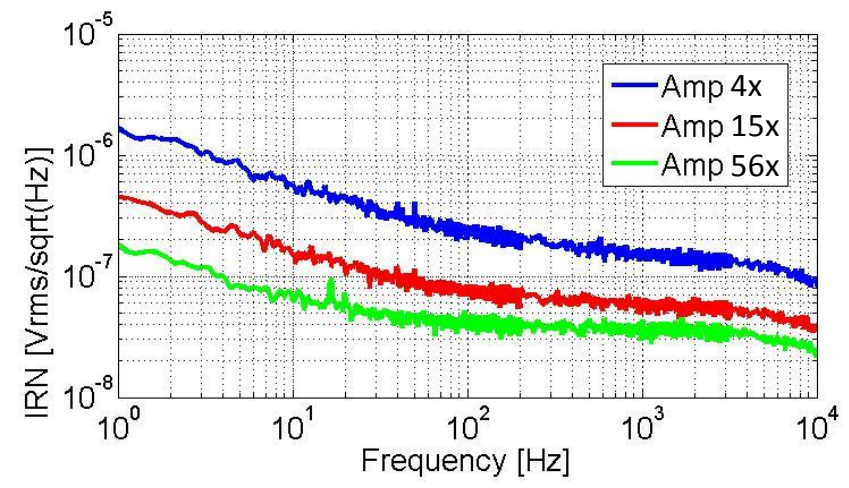

Fig. 18. Input referred noise of the IA at various gain settings

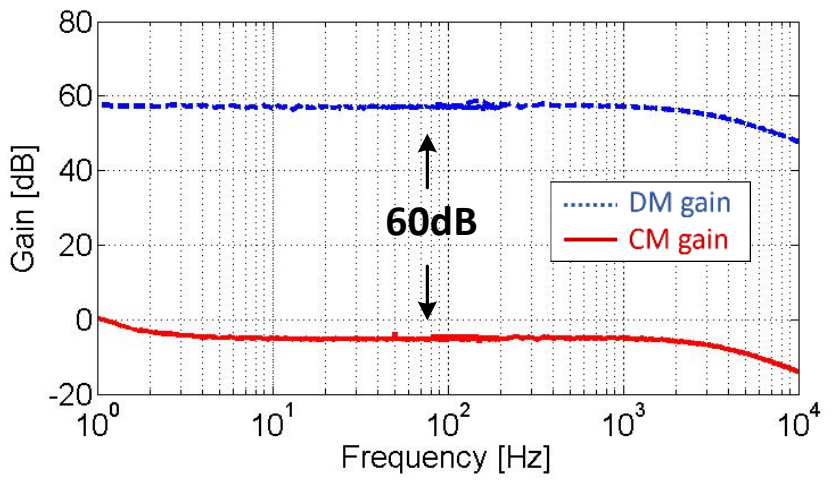

Fig. 19. Differential (blue) and common-mode gain of the IA

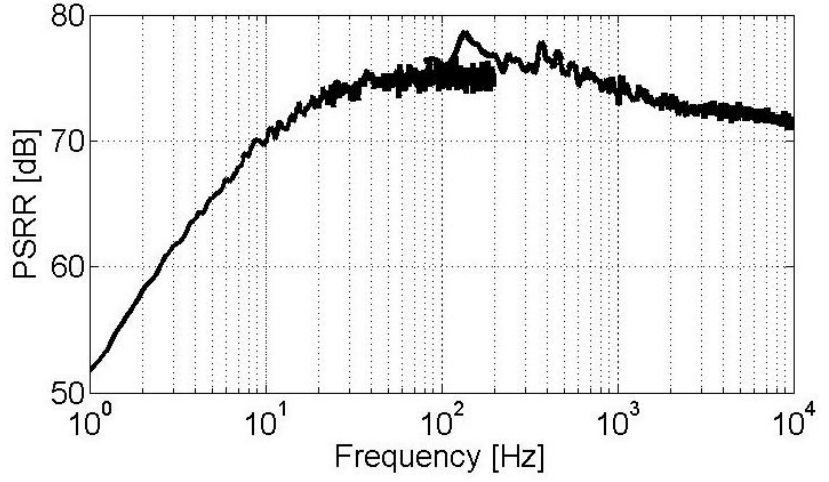

Fig. 20. PSRR of the IA

\section{B. ADC Performance}

In $12 \mathrm{~b}$ mode, the ADC achieves an ENOB of $10.4 \mathrm{~b}$ (Fig. 21) for input signals up to $50 \mathrm{kHz}$ and sampling rates of $100 \mathrm{kS} / \mathrm{s}$ and $5 \mathrm{MS} / \mathrm{s}$ at $1.8 \mathrm{~V}$ supply. In Fig. 22, the ADC's power dissipation scales linearly with the sampling rate up to $128 \mu \mathrm{W}$ at $5 \mathrm{MS} / \mathrm{s}$ and down to $8 \mathrm{nW}$ due to leakage. At $100 \mathrm{kS} / \mathrm{s}$, the FoM is $20 \mathrm{fJ} /$ conv.

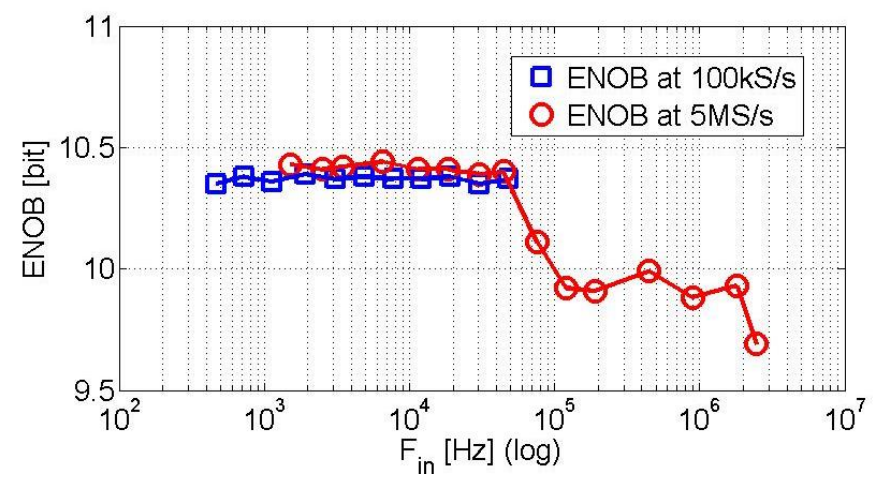

Fig. 21. ENOB of the ADC versus input frequency in $12 \mathrm{~b}$ mode

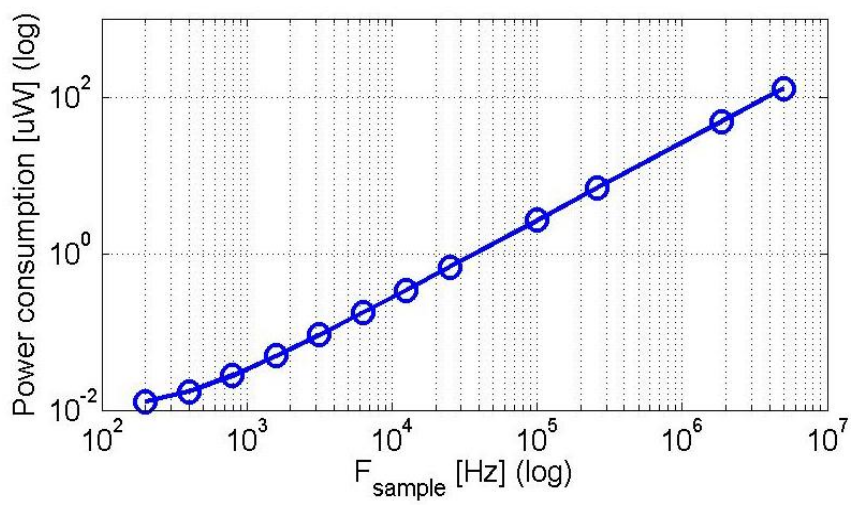

Fig. 22. Power consumption of the ADC versus sampling rate in $12 \mathrm{~b}$ mode

The resolution versatility of the 8-to-12 bit SAR ADC is demonstrated in Fig. 23 and Fig. 24, where the ADC is sampled at $100 \mathrm{kS} / \mathrm{s}$. Both the ENOB and the ADC's power dissipation scale monotonically with the resolution. The power also scales with $\mathrm{VDD}^{2}$ when the supply is reduced from $1.8 \mathrm{~V}$ down to $0.6 \mathrm{~V}$. Hence, various resolution modes can be selected based on the design specifications of sensitivity, dynamic range, and power budget.

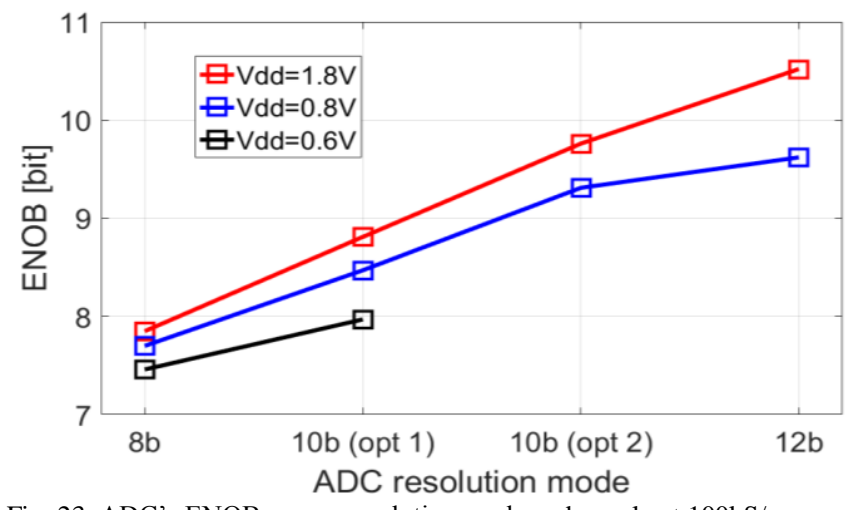

Fig. 23. ADC's ENOB versus resolution mode and supply at $100 \mathrm{kS} / \mathrm{s}$ 


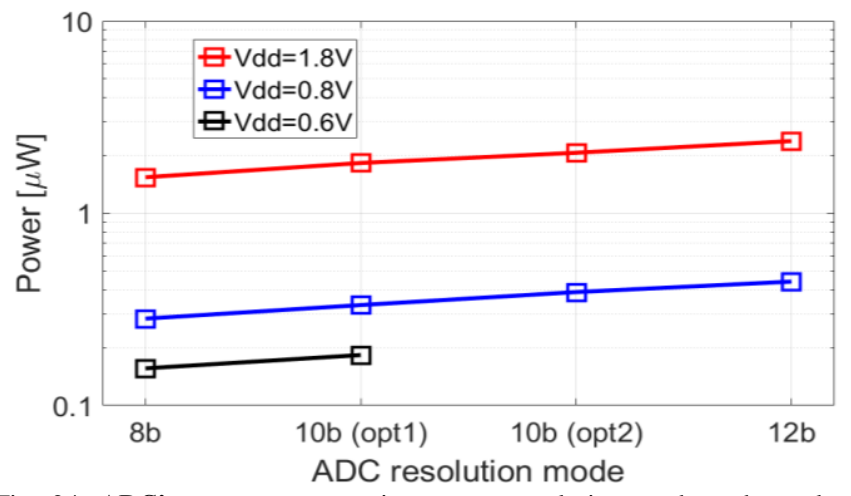

Fig. 24. ADC's power consumption versus resolution mode and supply at $100 \mathrm{kS} / \mathrm{s}$

\section{I-DAC Performance}

The (D)MLS excitation currents are verified by measuring the voltage across a load resistor of $1 \mathrm{k} \Omega$. Both modes have the same I-DAC settings. The measured (D)MLS voltages (Fig. 25) closely fit to the ideal simulation results (Fig. 6).

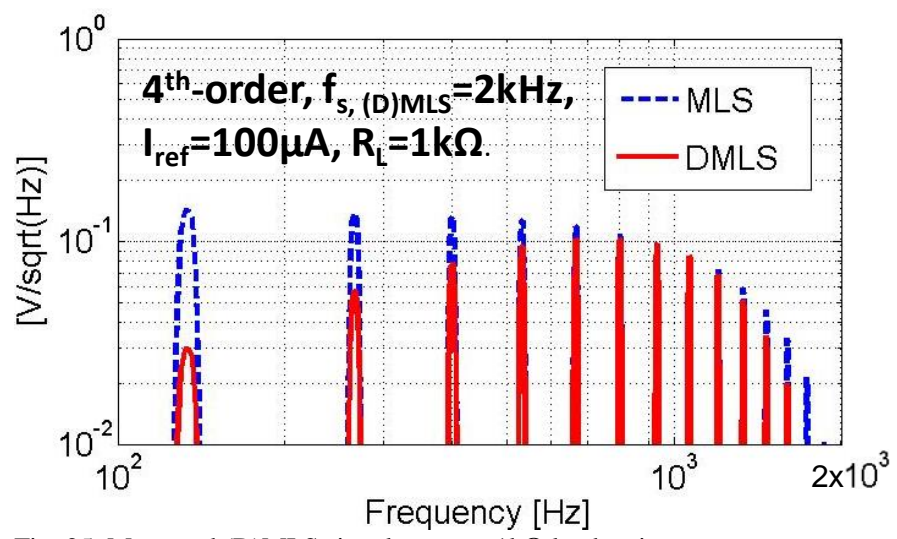

Fig. 25. Measured (D)MLS signal across a $1 \mathrm{k} \Omega$ load resistor

\section{System Performance}

This section shows the system performance by measuring discrete resistors and a RC complex impedance.

To determine the dynamic range, linearity and sensitivity, test resistors $(1 \mathrm{~m} \Omega$ to $220 \mathrm{k} \Omega)$ are measured. The resistor tests combine two IA gains $(4 \mathrm{x}, 56 \mathrm{x})$ and two current levels $(1 \mu \mathrm{A}$, $100 \mu \mathrm{A}$ ) to explore the maximum dynamic range (Fig. 26, Table II). The I-DAC outputs a $25 \mathrm{kS} / \mathrm{s} 4^{\text {th }}$-order MLS, while the ADC is $16 \mathrm{x}$ oversampled at $400 \mathrm{kS} / \mathrm{s}$ in the $12 \mathrm{~b}$ mode. The lowest test frequency (i.e. $25 \mathrm{kHz} / 15$ ) is used to determine the resistor value. For each of the two measurement ranges, a single calibration measurement is done as explained in Section II.C. Moreover, 2083x MLS sequences were averaged for improved sensitivity. Although more averaging could be used, this was limited by the test setup's buffer length. In total, 500k ADC samples (MLS length of 15, 16x oversampled, and 2083x averaged) are used to determine the resistor value, leading to a large gain in dynamic range. In Fig. 26, when the lowest current $(1 \mu \mathrm{A})$ is combined with the lowest IA gain $(4 \mathrm{x})$, the linear dynamic range is roughly $3.3 \Omega-100 \mathrm{k} \Omega$. When the highest current $(100 \mu \mathrm{A})$ is combined with the highest IA gain $(56 \mathrm{x})$, the linear dynamic range is roughly $3.3 \mathrm{~m} \Omega-100 \Omega$. In Fig. 27, the absolute resistor accuracy is derived from Fig. 26. While the accuracy is modest, this is acceptable for the intended BioZ applications. Some examples are measurements of impedance cardiography (ICG), respiration rate and body fluid volume, where key physiological features are represented by the relative BioZ change over time while the absolute BioZ may anyhow suffer from reproducibility errors due to daily intra-individual variability [1].

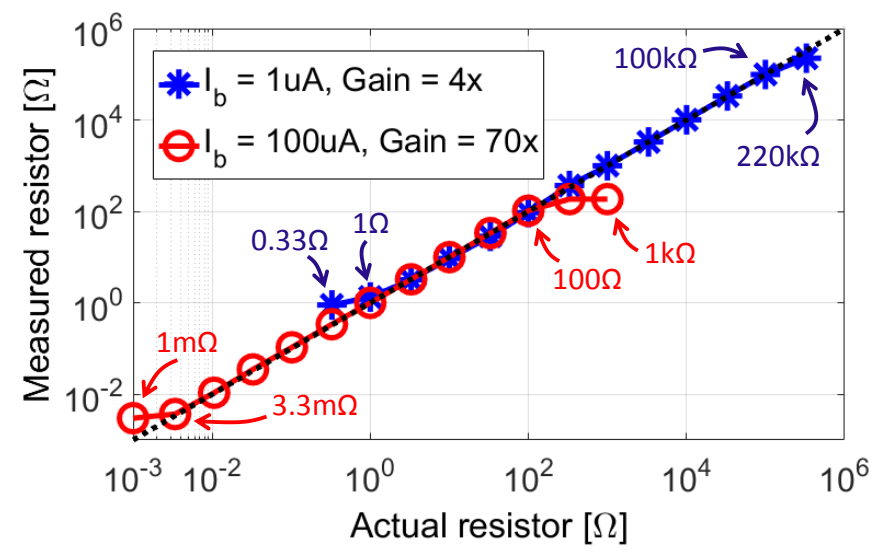

Fig. 26. Resistor measurement to explore the maximum dynamic range (after averaging 2083x MLS sequences)

The best sensitivities of $0.6 \Omega$ and $2 \mathrm{~m} \Omega$ for two different ranges are both achieved by averaging 2083x MLS sequences. As shown in Table II, in case of a low excitation current $(1 \mu \mathrm{A})$ and a low IA gain $(4 \mathrm{x})$, the standard deviation (noise) of the measured resistance is $28 \Omega$. This is achieved from one MLS sequence oversampled $16 x$ by the ADC. Further averaging a total number of 2083x MLS sequences reduces the standard deviation to $0.6 \Omega$, which is roughly a factor of $\sqrt{2} 2083$ better with respect to $28 \Omega$ as expected. Similarly, in case of a high current $(100 \mu \mathrm{A})$ and a high IA gain $(56 \mathrm{x})$, standard deviation of the measured resistance is $82 \mathrm{~m} \Omega$ for a single MLS sequence and it reduces to $2 \mathrm{~m} \Omega$ after averaging. As shown in Fig. 26 and Fig. $27,2 \mathrm{~m} \Omega$ and $0.6 \Omega$ are also close to the levels where the measured resistors become inaccurate $(>10 \%)$. The difference in non-averaged sensitivity between the two cases is $341 \mathrm{x}$. This is also expected as the excitation current is increased with $100 \mathrm{x}$ and the IA has about $4 \mathrm{x}$ lower input referred noise.

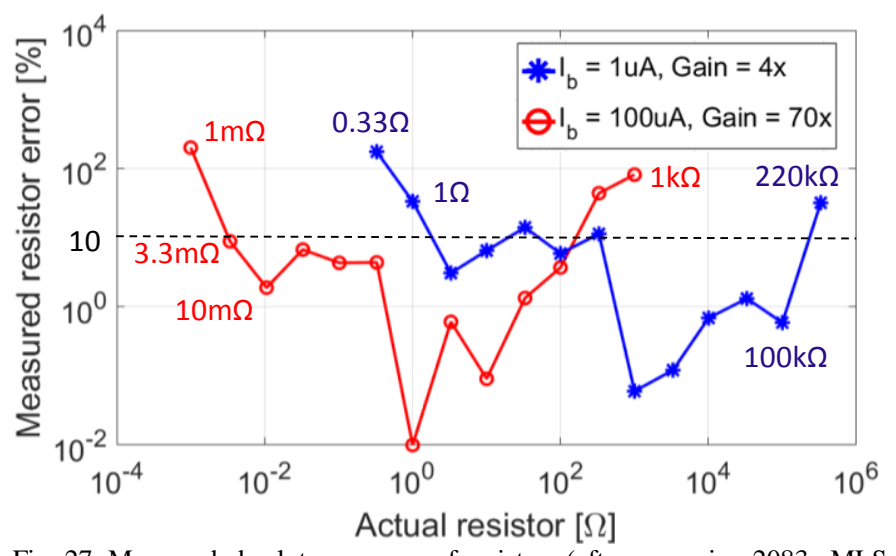

Fig. 27. Measured absolute accuracy of resistors (after averaging 2083x MLS sequences) 
TABLE II: MEASURED RESISTANCE STANDARD DEVIATION

\begin{tabular}{l|l|l}
\hline \hline \multicolumn{3}{l}{ System parameters } \\
\hline MLS frequency and order & $\mathrm{fs}=25 \mathrm{kS} / \mathrm{s}, 4^{\text {th }}$-order \\
\hline $\begin{array}{l}\text { ADC resolution and } \\
\text { sampling rate }\end{array}$ & \multicolumn{1}{l}{$\begin{array}{l}12 \mathrm{~b}, 400 \mathrm{kS} / \mathrm{s} \\
(16 \mathrm{x} \text { oversampling of MLS) }\end{array}$} \\
\hline IA voltage gain & 4 (lowest) & 56 (highest) \\
\hline Stimulation current & $1 \mu \mathrm{A}($ lowest $)$ & $100 \mu \mathrm{A}(\mathrm{highest})$ \\
\hline Input noise @ $1 \mathrm{kHz}$ & $162 \mathrm{nV} / \sqrt{ }(\mathrm{Hz})$ & $40 \mathrm{nV} / \sqrt{ }(\mathrm{Hz})$ \\
\hline Measurement results & \\
\hline $\begin{array}{l}\text { Standard deviation } \\
\text { (1x MLS, }\end{array}$ & $28 \Omega$ & $82 \mathrm{~m} \Omega$ \\
$0.6 \mathrm{~ms}$ measurement time) & & $2 \mathrm{~m} \Omega$ \\
\hline $\begin{array}{l}\text { Standard deviation } \\
\text { (averaging 2083x MLS, } \\
1.2 \mathrm{~s} \text { measurement time) }\end{array}$ & $0.6 \Omega$ & \\
\hline \hline
\end{tabular}

Combining both ranges leads to an overall linear dynamic range from $2 \mathrm{~m} \Omega$ to $100 \mathrm{k} \Omega$. Although BioZ is typically $<1 \mathrm{k} \Omega$, a large impedance tolerance of up to $100 \mathrm{k} \Omega$ is still beneficial for two-electrode BioZ measurements, where the skin-electrode impedance is measured in conjunction with BioZ.

Fig. 28 shows the bode plots of a complex impedance under different current excitation scenarios, where the MLS and the DMLS utilize different current levels, i.e. 2.5 $\mu$ A for the MLS and $50 \mu \mathrm{A}$ for the DMLS. In this way, their excitation currents are identical at $4 \mathrm{kHz}$ to fulfill the safe current requirements (Fig. 7a). As a reference test, the impedance was also measured with a $50 \mu \mathrm{A}$ MLS current, even though this would not meet the safe current regulation.
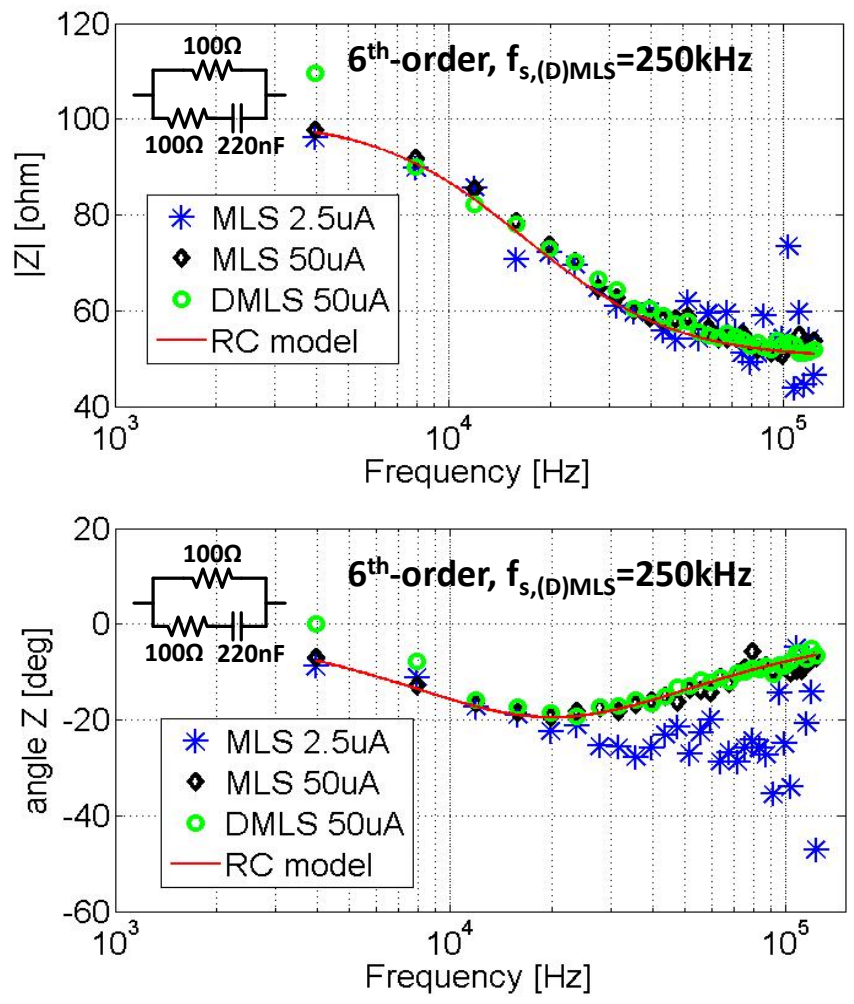

Fig. 28. Measured magnitude and phase of a complex impedance with the same and different (D)MLS currents

Fig. 28 verifies that the $50 \mu \mathrm{A}$ MLS ensures the best accuracy over a $125 \mathrm{kHz}$ bandwidth but it violates the safe current limits.
Reducing the MLS current to $2.5 \mu \mathrm{A}$ solves the safety issue at the cost of less accuracy at high frequencies due to the limited IA bandwidth and the decreased BioZ. As a solution, utilizing a $50 \mu \mathrm{A}$ DMLS current meets the safe current limits and achieves better accuracy, except for the very lowest frequencies. There, the performance is degraded due to a much lower excitation current. Overall, DMLS performs best over most of the bandwidth, while MLS can be better for very low frequencies.

Fig. 29 shows Cole-Cole plot of another complex impedance to mimic the BioZ on the chest. The (D)MLS have the same current magnitude at the highest frequency, similar as shown in Fig. 25. The measurement took only $1 \mathrm{~ms}$, including $8 \mathrm{x}$ ADC oversampling and $4 \mathrm{x}$ averaging of (D)MLS sequences. The total power dissipation is $155 \mu \mathrm{W}$ (or $155 \mathrm{~nJ}$ per measurement), including $91 \mu \mathrm{W}$ from the I-DAC, $12.6 \mu \mathrm{W}$ from the IA and $51 \mu \mathrm{W}$ from the ADC sampling at $2 \mathrm{MS} / \mathrm{s}$.

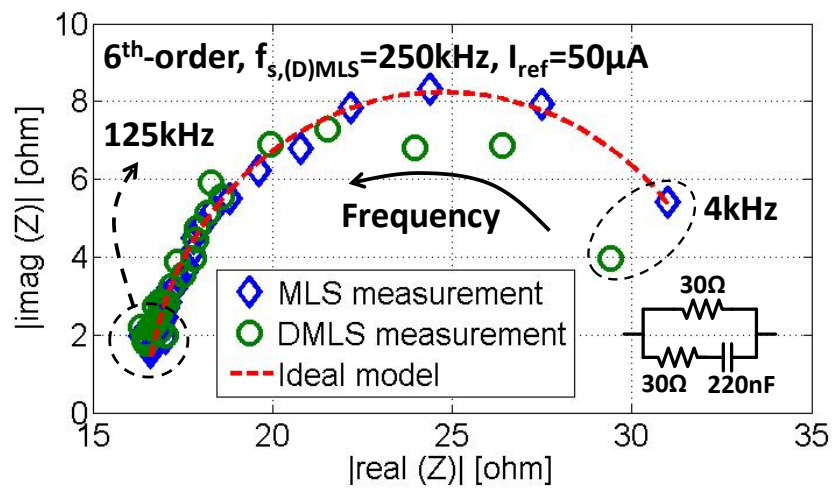

Fig. 29. The Cole-Cole plot of a complex impedance measured with the same (D)MLS current

\section{E. ECG/BioZ Measurement}

For simultaneous measurement of BioZ and ECG across the body (Fig. 1), two excitation electrodes were placed on the left and right wrists, and two recording electrodes were placed on the chest across the heart. The system parameters and signal processing are the same as described in Fig. 10. A respiratory impedance of about $2 \Omega_{\mathrm{pp}}$ is shown in Fig. 30. A $9.5 \Omega$ baseline impedance represents the static tissue resistance between two recording electrodes on the chest. The periodical "spikes" on the measured BioZ reflect the impedance change due to blood movement in the thoracic cavity, also known as the impedance cardiography (ICG).

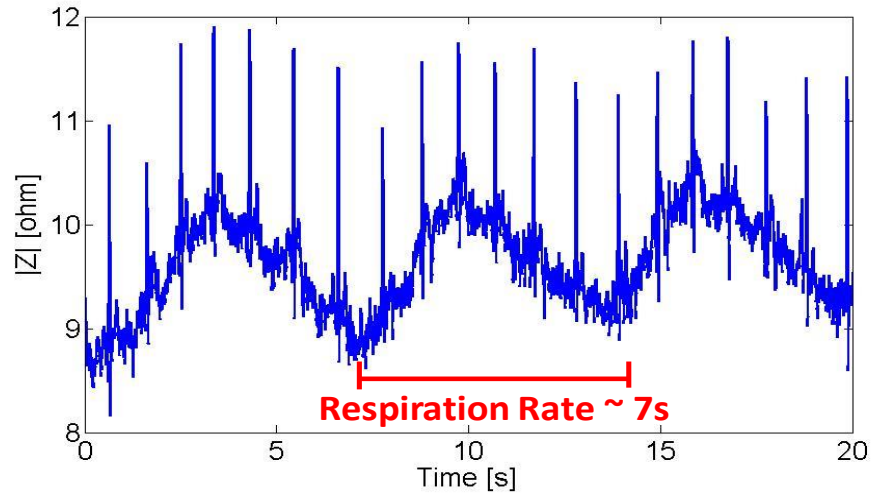

Fig. 30. Respiratory impedance with wrist excitation and chest recording 
TABLE III: COMPARISON TABLE OF THE (BIO-) IMPEDANCE MEASUREMENT ICS

\begin{tabular}{|c|c|c|c|c|c|c|c|}
\hline & $\begin{array}{c}\text { TCASII'16 } \\
\text { [18] }\end{array}$ & $\begin{array}{c}\text { JSSC'15 } \\
{[6]}\end{array}$ & $\begin{array}{c}\text { TBioCAS'16 } \\
\text { [29] }\end{array}$ & $\begin{array}{c}\text { ESSCIRC'17 } \\
{[8]}\end{array}$ & $\begin{array}{c}\text { ADS1292R } \\
{[30]}\end{array}$ & $\begin{array}{c}\text { ISSCC'14 } \\
{[9]}\end{array}$ & This work \\
\hline Technology & $0.13 \mu \mathrm{m}$ & $0.18 \mu \mathrm{m}$ & $0.15 \mu \mathrm{m}$ & $0.18 \mu \mathrm{m}$ & N/A & $0.18 \mu \mathrm{m}$ & $0.18 \mu \mathrm{m}$ \\
\hline Supply & $1.2 \mathrm{~V}$ & $1.8 \mathrm{~V}$ & $1.8 \mathrm{~V}$ & $1.8 \mathrm{~V}$ & $3 \mathrm{~V}$ & $1.2 \mathrm{~V}$ & $1.8 \mathrm{~V}$ \\
\hline Functionalities & BioZ & BioZ & BioZ & BioZ & $\begin{array}{c}\text { BioZ, ECG } \\
\text { (two IAs) }\end{array}$ & $\begin{array}{c}\text { BioZ, ECG } \\
\text { (two IAs) }\end{array}$ & $\begin{array}{l}\text { BioZ, ECG } \\
\text { (single IA) }\end{array}$ \\
\hline $\begin{array}{l}\text { Excitation } \\
\text { modes }\end{array}$ & $\begin{array}{l}\text { multi-f } \\
\text { square }\end{array}$ & $\begin{array}{l}\text { multi-f } \\
\text { sine }\end{array}$ & $\begin{array}{l}\text { multi-f } \\
\text { sine }\end{array}$ & $\begin{array}{c}\text { single-f } \\
\text { pseudo-sine }\end{array}$ & $\begin{array}{l}\text { multi-f } \\
\text { square }\end{array}$ & $\begin{array}{c}\text { dual-f } \\
\text { square-wave }\end{array}$ & $\begin{array}{c}\text { broadband } \\
\text { MLS/DMLS }\end{array}$ \\
\hline $\begin{array}{c}\text { Current } \\
\text { magnitude }\end{array}$ & $0-196 \mu \mathrm{A}$ & $10-400 \mu \mathrm{A}$ & $1.1-10 \mu \mathrm{A}$ & $26 \mu \mathrm{A}$ & $30 \mu \mathrm{A}$ & $27-117 \mu \mathrm{A}$ & $1-100 \mu \mathrm{A}$ \\
\hline Bandwidth & $250-1.24 \mathrm{MHz}$ & $100-100 \mathrm{kHz}$ & $2 \mathrm{k}-2 \mathrm{MHz}$ & $20 \mathrm{kHz}$ & $32 \mathrm{k} / 64 \mathrm{kHz}$ & $20 \mathrm{k} / 40 \mathrm{kHz}$ & $<125 \mathrm{kHz}$ \\
\hline $\begin{array}{l}\text { Frequency } \\
\text { points }\end{array}$ & 6 bit & 2 bit & 3 bit & 0 bit & 1 bit & $1 \mathrm{bit}$ & 6 bit \\
\hline $\begin{array}{l}\text { BioZ dynamic } \\
\text { range }\end{array}$ & $\begin{array}{c}8.7 \mathrm{~m}-600 \Omega \\
(97.1 \mathrm{~dB}) \\
\end{array}$ & $10-10 \mathrm{k} \Omega$ & $50 \Omega-11 \mathrm{k} \Omega$ & $87 \mathrm{~dB}$ & $<10 \mathrm{k} \Omega$ & $10 \mathrm{k} \Omega$ & $\begin{array}{l}<100 \Omega \text { to } \\
<100 \mathrm{k} \Omega\end{array}$ \\
\hline $\begin{array}{c}\text { BioZ } \\
\text { sensitivity }\end{array}$ & $8.7 \mathrm{~m} \Omega$ & $4.9 \mathrm{~m} \Omega$ & $1 \Omega$ & $38.5 \mathrm{~m} \Omega$ & $40 \mathrm{~m} \Omega$ & $200 \mathrm{~m} \Omega$ & $2 \mathrm{~m} \Omega$ to $0.6 \Omega$ \\
\hline $\begin{array}{c}\text { Input referred } \\
\text { noise (ECG) }\end{array}$ & -- & -- & -- & -- & $\begin{array}{l}0.8 \mu \mathrm{Vrms} \\
(0-131 \mathrm{~Hz})\end{array}$ & $\begin{array}{c}0.61 \mu \mathrm{Vrms} \\
(0.5-150 \mathrm{~Hz})\end{array}$ & $\begin{array}{c}0.91 \mu \mathrm{Vrms} \\
(0.5-150 \mathrm{~Hz})\end{array}$ \\
\hline $\mathrm{ADC}$ & $12 b$ & $14 \mathrm{~b}$ & -- & N/A & $24 \mathrm{~b}$ & $12 \mathrm{~b}$ & 8 -to-12b \\
\hline $\begin{array}{c}\text { Power for BioZ } \\
\text { mode }\end{array}$ & $52 \mu \mathrm{W}$ & $\begin{array}{c}53.4 \mathrm{~mW} \\
(6 \text { channels })\end{array}$ & $297 \mu \mathrm{W}$ & $24 \mu \mathrm{W}$ & $425 \mu \mathrm{W}$ & $58 \mu \mathrm{W}$ & $\begin{array}{c}\text { ECG + BioZ: } \\
31 \mu \mathrm{W} \text { at } 20 \mathrm{kS} / \mathrm{s}, \\
(\mathrm{I}-\mathrm{DAC}: 10 \mu \mathrm{A})\end{array}$ \\
\hline $\begin{array}{c}\text { Power for ECG } \\
\text { mode }\end{array}$ & -- & -- & -- & -- & $335 \mu \mathrm{W}$ & $31 \mu \mathrm{W}$ & $\begin{array}{c}\text { or } \\
155 \mu \mathrm{W} \text { at } 2 \mathrm{MS} / \mathrm{s} \text {, } \\
\text { (I-DAC: } 50 \mu \mathrm{A})\end{array}$ \\
\hline
\end{tabular}

The simultaneously measured ECG and ICG with the same 4-electrode setup are shown in Fig. 31. The ECG exhibits clear $\mathrm{P}$ wave, QRS complex, and T wave, while the ICG shows the key features of the cardiac cycle, including B-point (represents the opening of the aortic valve), $\mathrm{X}$-point (represents the closing of the aortic valve) and C-point (represents the maximal speed of blood ejection). The total power dissipation in simultaneous ECG and BioZ/respiration mode is $31 \mu \mathrm{W}$, including $18.1 \mu \mathrm{W}$ for the I-DAC, $12.6 \mu \mathrm{W}$ for the IA and $0.5 \mu \mathrm{W}$ for the ADC sampling at $20 \mathrm{kS} / \mathrm{s}$.
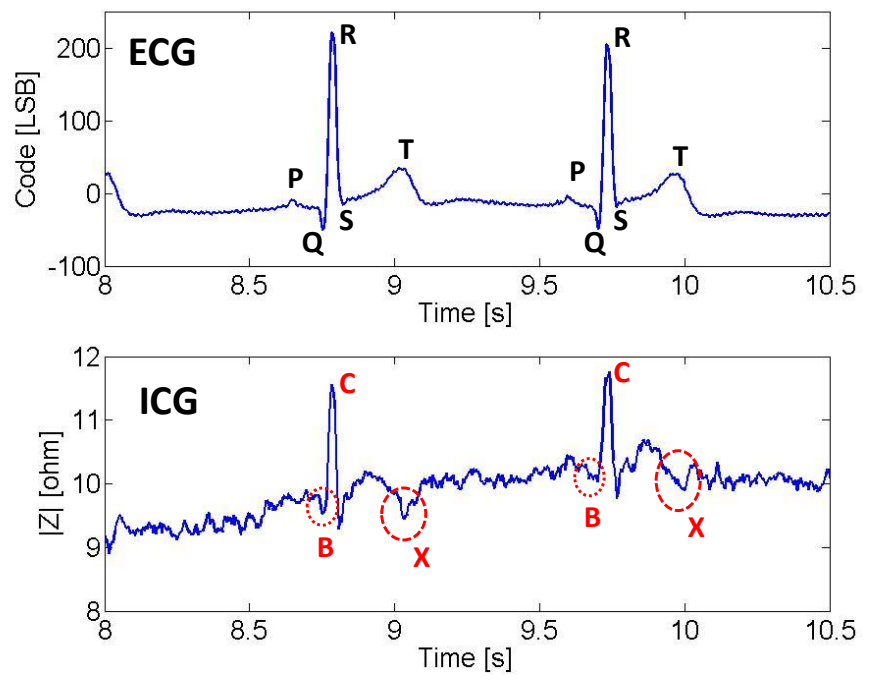

Fig. 31. Simultaneous measurement of ECG and ICG with the same recording electrodes on the chest

Table III compares this work with recently published BioZ acquisition ICs. The work advances over other designs in terms of the most reconfigurable parameters, e.g. excitation modes, measurement bandwidth, I-DAC magnitude, frequency points, dynamic range and ADC resolution. Reference calibration and averaging of the (D)MLS sequences in post signal processing helps the IC to $2 \mathrm{~m} \Omega$ sensitivity over $100 \Omega$ range. In addition, the proposed IC consumes the lowest power of only $31 \mu \mathrm{W}$ for simultaneous ECG/ICG, BioZ and respiration measurement.

\section{CONCLUSION}

This paper presented a power-efficient and reconfigurable sensor IC simultaneous BioZ, ECG and respiration recording. The scaling between circuit performance and power is realized on both system and circuit levels. The (D)MLS excitation with calibration enables a BioZ spectroscopy up to $125 \mathrm{kHz}$, a factor of 3.5x beyond the IA's intrinsic bandwidth. The 8-to-12 bit SAR ADC, with several low-power and dynamic techniques, enables a sample rate up to 5MS/s and thus facilitates the use of oversampling and averaging the (D)MLS sequences for noise reduction. This IC achieves the best BioZ sensitivity of $2 \mathrm{~m} \Omega$ while consuming $155 \mu \mathrm{W}$. In another configuration, respiration, ECG and ICG were measured simultaneously while consuming only $31 \mu \mathrm{W}$.

\section{REFERENCES}

[1] U.G. Kyle et al. Bioelectrical impedance analysis - part I. Review of principles and methods. Clin Nutr, pp.1226-1243, Oct. 2004.

[2] $\mathrm{CM}$. Yu, L. Wang et al., "Intrathoracic impedance monitoring in patients with heart failure: correlation with fluid status and feasibility of early warning" preceding hospitalization", Circulation, pp. 841-848, 2005.

[3] S. Dovancescu et al., "Detection of electrocardiographic and respiratory signals from transthoracic bioimpedance spectroscopy measurements with a wearable monitor for improved home-based disease management in congestive heart failure", IEEE Computing in Cardiology Conference (CinC), pp. 985-988, Sep. 2014. 
[4] N. Van Helleputte et al., "A $160 \mu \mathrm{W}$ biopotential acquisition IC with fully integrated IA and motion artifact suppression," IEEE Trans on Biomed Circuits and Systems. vol.6, no.6, pp.552-561, Dec. 2012.

[5] Q. Fan, J. H. Huijsing and K. A. A. Makinwa, A $1.8 \mu \mathrm{W} 60 \mathrm{nV} / \sqrt{\mathrm{Hz}}$ capacitively-coupled chopper instrumentation amplifier in 65nm CMOS for wireless sensor nodes," IEEE J. Solid-State Circuits, vol. 46, no. 7, pp. 1534-1543, Jul. 2011.

[6] S. Hong, K. Lee et al., "A $4.9 \mathrm{~m} \Omega$-sensitivity mobile electrical impedance tomography IC for early breast-cancer detection system," IEEE J. Solid-State Circuits, vol. 50, no. 1, pp. 245-257, Jan. 2015.

[7] P. Kassanos, L. Constantinou et al., "An integrated analog readout for multi-frequency bioimpedance measurements". IEEE Sensors Journal, vol. 14, no. 8, pp. 2792-2800, Aug. 2014.

[8] K. Kim et al., "A $24 \mu \mathrm{W} 38.51 \mathrm{~m} \Omega_{\mathrm{rms}}$ resolution bio-impedance sensor with dual path instrumentation amplifier," Proc. ESSCIRC, pp. 223-226. Sept. 2017.

[9] N. Van Helleputte et al., "A multi-parameter signal-acquisition SoC for connected personal health applications", Digest of ISSCC, pp. 314-315, Feb. 2014.

[10] T. Sun, D. Holmes et al, "High speed multi-frequency impedance analysis of single particles in a microfluidic cytometer using maximum length sequences," Lab on a Chip, issue 7, pp. 1034-1040, Aug. 2007.

[11] AAMI ES1, "Safe current limits for electromedical apparatus," 1993.

[12] J. Xu, P. Harpe et al., "A low power configurable bio-impedance spectroscopy (BIS) ASIC with simultaneous ECG and respiration recording functionality", Proc. ESSCIRC, pp.396-399. Sept. 2015.

[13] A. K. Gupta "Respiration Rate Measurement Based on Impedance Pneumography", Application Report, Texas Instruments, Feb. 2011.

[14] J. C. Conchell., "Bio-impedance circuit design for body worn systems."

[15] IEC 60601-2-27, Medical electrical equipment - Part 2-27: "Particular requirements for the basic safety and essential performance of electrocardiographic monitoring equipment," 2011.

[16] IEC 60601-2-47, Medical electrical equipment - Part 2-47: "Particular requirements for the basic safety and essential performance of ambulatory electrocardiographic systems," 2012.

[17] I. F. Triantis, A. Demosthenous et al., "A multi-frequency bioimpedance measurement ASIC for electrical impedance tomography", Proc. of ESSCIRC, pp.331-334. Sept. 2011.

[18] H. Ko, T. Lee et al., "Ultralow-power bioimpedance IC with intermediate frequency shifting chopper," IEEE Trans. on Circuits and Systems II, vol. 63, no. 3, pp. 259-263, March. 2016.

[19] C.K. Fuller et al., "Microfabricated multi-frequency particle impedance characterization system" Micro Total Analysis Systems, pp. 265-268, May. 2000.

[20] D. D. Rife et al., "Transfer-function measurement with maximum length sequences," J. Audio Eng. Soc., vol. 37, pp. 419-444, June. 1989.

[21] J. D. Techer, S. Bernard, Y. Bertrand, G. Cathebras, and D. Guiraud, "New implantable stimulator for the FES of paralyzed muscles," Proc. of ESSCIRC, pp.455-458. Sept. 2004

[22] R. F. Yazicioglu, P. Merken et al., "A $60 \mu \mathrm{W} 60 \mathrm{nV} / \sqrt{\mathrm{Hz}}$ readout front-end for portable biopotential acquisition systems," IEEE J. Solid-State Circuits, vol. 42, no 5, pp. 1100-1110, May. 2007.

[23] Y. Shen, Z. Zhu, S. Liu and Y. Yang, "A Reconfigurable 10-to-12-b 80-to-20-MS/s Bandwidth Scalable SAR ADC," IEEE Trans on Circuits and Systems I: Regular Papers, vol. 65, no. 1, pp. 51-60, Jan. 2018.

[24] P. Harpe et al., "A 7-to-10b 0-to-4MS/s flexible SAR ADC with 6.5-16fJ/conversion-step", Digest of ISSCC, pp.472-474, Feb. 2012.

[25] M. van Elzakker et al., "A 10-bit charge-redistribution ADC consuming $1.9 \mu \mathrm{W}$ at $1 \mathrm{MS} / \mathrm{s}$," IEEE J. Solid-State Circuits, vol. 45, no 5, pp. 1007-1015, May. 2010.

[26] C. C. Liu et al., "A 10-bit 50-MS/s SAR ADC with a monotonic capacitor switching procedure," IEEE J. Solid-State Circuits, vol. 45, no. 4, pp. 731-740, April 2010.

[27] S. Liu, Y. Shen and Z. Zhu, "A 12-Bit $10 \mathrm{MS} / \mathrm{s}$ SAR ADC With High Linearity and Energy-Efficient Switching," IEEE Trans on Circuits and Systems I: Regular Papers, vol. 63, no. 10, pp. 1616-1627, Oct. 2016.

[28] M. Ding et al., "A 5.5fJ/conv-step 6.4MS/s 13b SAR ADC Utilizing a Redundancy-Facilitated Background Error-Detection-and-Correction Scheme," Digest of ISSCC, pp. 460-461, Feb. 2015.

[29] S. Rodriguez, S. Ollmar, M. Waqar and A. Rusu, "A batteryless sensor ASIC for implantable bio-impedance applications," IEEE Trans on Biomed Circuits and Systems, vol. 10, no. 3, pp. 533-544, June. $2016 .$.

[30] ADS1292R datasheet, Texas Instruments.

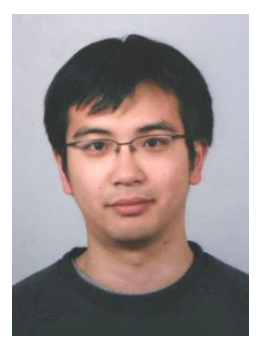

Jiawei Xu (M'14) received the M.Sc. and Ph.D. degrees in electrical engineering from the Delft University of Technology, The Netherlands, in 2006 and 2016, respectively.

Since 2006, he started working at imec/Holst Centre, Eindhoven, The Netherlands, where he developed low-power biomedical ICs for EEG, ECG, bio-impedance, galvanic skin response, and near-infrared spectroscopy. He is currently Senior Researcher and leading the IC design for noninvasive brain monitoring.

Dr. Xu was the recipient of the IEEE Solid-State Circuits Society Predoctoral Achievement Award (2014) and the imec Scientific Excellence Award (2014).

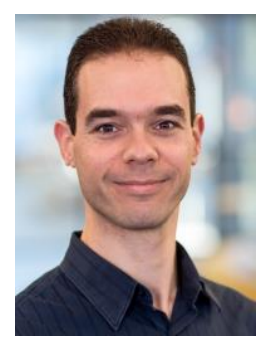

Pieter Harpe (SM'15) received the M.Sc. and Ph.D. degrees from the Eindhoven University of Technology, The Netherlands, in 2004 and 2010, respectively.

In 2008, he started as researcher at Holst Centre/imec, The Netherlands. Since then, he has been working on ultra low-power wireless transceivers, with a main focus on ADC research and design. In April 2011, he joined Eindhoven University of Technology where he is currently an Associate Professor on low-power mixed-signal circuits.

Dr. Harpe is co-organizer of the yearly workshop on Advances in Analog Circuit Design (AACD) and analog subcommittee chair for the ESSCIRC conference. He also served as ISSCC ITPC member and IEEE SSCS Distinguished Lecturer and is recipient of the ISSCC 2015 Distinguished Technical Paper Award.

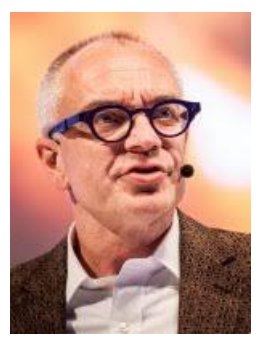

Chris Van Hoof received the Ph.D. degree in electrical engineering from the University of Leuven, Belgium, in 1992. He is currently the Senior Director of Wearable Healthcare at imec and imec Fellow, with a track record of over 25 years of initiating, executing, and leading national and international contract $\mathrm{R} \& \mathrm{D}$ at imec.

His work resulted in three startups (two in the healthcare domain) and he has delivered sensor flight hardware to two cornerstone European Space Agency missions. After receiving his Ph.D. from the University of Leuven in 1992 in collaboration with imec, he has held positions at imec as manager and director in diverse technical fields (sensors and imagers, MEMS and autonomous microsystems, wireless sensors, and body-area networks, wearable health). He has published over 600 papers in journals and conference proceedings and given over 60 invited talks. He is also full professor at the University of Leuven (KU Leuven). 